\title{
Endothelial Cells Promote Calcification in Aortic Smooth Muscle Cells from Spontaneously Hypertensive Rats
}

\author{
Fanxing Meng Yonggang Zhao Bing Wang Bingwei Li Youming Sheng \\ Mingming Liu Hongwei Li Ruijuan Xiu \\ Institute of Microcirculation, Key Laboratory of Microcirculation, Ministry of Health, Chinese Academy \\ of Medical Sciences \& Peking Union Medical College, Beijing, China
}

\section{Key Words}

Aorta $\cdot$ Endothelial cells $\cdot$ Smooth muscle cells $\cdot$ Spontaneously hypertensive rats $•$ Vascular calcification

\begin{abstract}
Background/Aims: Vascular calcification and hypertension are intimately linked, and the progression of hypertension is closely correlated with endothelial dysfunction. However, the role of endothelial cells (ECs) in vascular calcification of hypertension remains unclear. Therefore, the present study explored the effects of ECs on calcification of smooth muscle cells (SMCs) from aortas of spontaneously hypertensive rats (SHR). Methods: Aortic ECs and SMCs were isolated from SHR and Wistar rats, respectively. The roles of ECs in the regulation of SMCs calcification were investigated by co-culture and conditioned culture model. Calcium deposition of SMCs was detected by von Kossa staining. Quantization of calcium content in SMCs was determined colorimetrically by the o-cresolphthalein complexone method. Alkaline phosphatase (ALP) activity was measured colorimetrically by $p$-nitrophenol. The expression levels of MMP-2, MMP-9 and the calcification-promoting proteins were analyzed by Western blot. Results: Calcium deposition, ALP activity and the expression levels of calcificationpromoting proteins in SMCs of SHR were significantly higher than that cultured without ECS after 6 days of co-culture with ECs or conditioned culture with the medium of ECs, however, there were no statistical differences between SMCs of Wistar rats. MMP-2 and MMP-9 in cocultured ECs from SHR were dramatically higher than that cultured without SMCs, nevertheless, there were no statistical differences between ECs from Wistar rats and between SMCs from SHR or Wistar rats. Moreover, SB-3CT, a specific inhibitor of gelatinases, decreased calcium content and the expression levels of calcification-promoting proteins in both co-cultured and conditionally cultured SMCs from SHR. Conclusion: ECs have the ability to promote calcification of aortic SMCs of SHR, and elevated expressions of MMP-2 and MMP-9 in ECs of SHR might facilitate the calcification of SMCs.




\section{Cellular Physiology Cell Physiol Biochem 2018;49:2371-2381

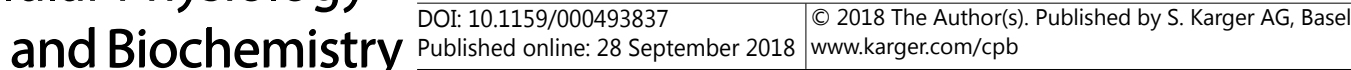 \\ Meng et al.: ECs Promote Calcification in SMCs of SHR}

\section{Introduction}

Vascular calcification is an abnormal deposition of calcium in blood vessels [1]. It is associated with a high cardiovascular risk and has a much greater prevalence in patients with atherosclerosis, hypertension, diabetes mellitus, aortic stenosis and other cardiovascular diseases. Hypertension and vascular calcification are intimately linked and potentiates each other [2]. Calcification may contribute to decreased elasticity and increased stiffness of the artery wall, which accelerates pulse wave velocity, thereby widening the pulse pressure and promoting the occurrence of hypertension [3-5]. Commonly, patients with resistant hypertension have severe arterial calcification, and resistant hypertension may be explained by the role of arterial calcification [6]. Furthermore, arterial calcification is independently correlated to arterial stiffness and is a major cause of cardiovascular mortality $[7,8]$. These reports indicate that understanding the mechanisms of calcification may offer new therapies for hypertension [2].

Vascular calcification was previously considered as a passive and uncontrolled process. Accumulating evidences demonstrate it is an actively regulated process which is similar to bone formation with competition between local and systemic inhibitors and promoters [9]. Mineralization may proceed since osteoblast-like cells resides in the vascular wall [10]. Based on the location of calcium deposition, vascular calcification is generally divided into intimal calcification and medial calcification. The medial calcification occurs preferentially along the elastic lamina, as opposed to the diffuse localization seen in intimal calcification [10].

Hypertension is associated with medial calcification [2]. The medial layer of the vessel wall is composed of smooth muscle cells (SMCs) and extracellular matrix. SMCs are generally regarded as the origin of the osteoblast-like cells. Following the injurious stimuli, such as mechanical forces, vasoactive agents, humoral factors and inflammatory mediators, SMCs might be converted from contractile phenotype to synthetic phenotype, and present as osteoblast-like cells [11]. The process of differentiation may be promoted by bone morphogenetic protein 2 (BMP2), runt-related transcription factor 2 (Runx2), Msx2, and Osterix [12-15].

Recent studies have shown that endothelial cells (ECs) were involved in the regulation of vascular calcification [16]. ECs undergo endothelial-mesenchymal transitions and contribute to the ectopic ossification in fibrodysplasia ossificans progressive [17]. Cola et al. reported that calcification of arterial wall might be regulated by ECs. The expressions of genes that facilitate arterial calcification were up-regulated when ECs were exposed to atherosclerotic and pro-inflammatory stimuli [18]. However, the role of ECs in vascular calcification of hypertension remains unclear.

The progression of hypertension is closely correlated with endothelial dysfunction [19]. Schmid-Schönbein et al. revealed that matrix metalloproteinase-2 (MMP-2) and MMP-9 were highly expressed in the endothelium of spontaneously hypertensive rats (SHR), and MMP-2 and MMP-9 secreted by ECs in SHR cleaved the extracellular domain of vascular endothelial growth factor receptor-2, which in turn caused endothelial apoptosis and capillary rarefaction [20, 21]. Mounting evidences indicated that elevated activity or expression of MMP-2 and MMP-9 lead to vascular calcification [22, 23]. Furthermore, hypertension impairs endothelial function, leading to an imbalance of endothelial autocrine-paracrine factors that maintain normal vascular function. Subsequently, the release of vaso-active substances promote smooth muscle cells proliferation, migration, and phenotypic transformation [19, 24]. Therefore, we hypothesize that ECs have the ability to promote osteogenic transition of SMCs in hypertension, and elevated expressions of MMP-2 and MMP-9 in ECs of SHR might be involved in the process.

In the present study, aortic ECs and SMCs were isolated from SHR and Wistar rats, respectively. The alterations of calcium deposition, alkaline phosphatase (ALP) activity and the expressions of calcification - regulating related protein in SMCs or ECs were investigated 


\section{Cellular Physiology Cell Physiol Biochem 2018;49:2371-2381 and Biochemistry \begin{tabular}{l|l} 
DOI: 10.1159/000493837 \\
Published online; 285eptember 2018
\end{tabular} $\begin{aligned} & \text { O } 2018 \text { The Author(s). Published by S. Karger AG, Basel } \\
& \text { wwr.com/cpb }\end{aligned}$ \\ Meng et al.: ECs Promote Calcification in SMCS of SHR}

by using conditioned culture and co-culture model, and the effects of ECs on calcification of SMCs in SHR could be illustrated.

\section{Materials and Methods}

\section{Animals}

Male Wistar rats and SHR at 9 weeks of age were obtained from Vital River Laboratory Animal Technology Co., Ltd (Beijing, China). All experimental procedures involving the use and care of animals were conducted in accordance with protocol guidelines approved by Experimental Animal Committee of Institute of Microcirculation, Chinese Academy of Medical Sciences \& Peking Union Medical College.

\section{Cell culture}

Both ECs and SMCs were isolated from the descending thoracic aortic of rats, and identified as described previously $[25,26]$. The growing media used for all cell types were Dulbecco's modified Eagles' medium (DMEM; high glucose, 4.5 g/L; Life Technologies Inc., Gaithersburg, Maryland, USA) containing 10\% fetal bovine serum (FBS; Life Technologies Inc., USA), supplemented with 3 mmol/L L-glutamine, 100 $\mathrm{U} / \mathrm{mL}$ penicillin and $100 \mu \mathrm{g} / \mathrm{mL}$ streptomycin. ECs and SMCs between passages 3 and 5 were used for all experiments. SMCs without ECs means SMCs cultured in the absence of either ECs or conditioned medium of ECs.

ECs isolated from rat aorta are likely to be contaminated by very few fibroblasts. Even though a minimum number of fibroblasts mix in ECs, the cellular microenvironment may be changed and the role of ECs is probably affected in the culture system. Therefore, fibroblasts serving as negative control is prerequisite to prove the promoting - calcification potential of ECs. Fibroblasts were isolated from the aorta of rats, and identified as described previously $[27,28]$. The culture method of fibroblasts was the same as ECs.

\section{Transwell co-culture}

SMCs $\left(3.5 \times 10^{5} /\right.$ well $)$ were cultured in a 6-well dish. After the confluence of SMCs, the transwell chambers (polycarbonate membranes with $3 \mu \mathrm{m}$ pores; Corning Life Sciences, California, USA) plated with ECs or fibroblasts $\left(1 \times 10^{5} /\right.$ well $)$ were inserted in the wells [25]. The transwell allows exchange of the medium, however, cell-cell contact between SMCs and ECs or fibroblasts was inhibited by polycarbonate membranes. Media were replenished every 3 days.

\section{Conditioned culture}

SMCs $\left(3.5 \times 10^{5} /\right.$ well) were cultured in a 6-well dish. After the confluence of SMCs, ECs or fibroblasts $\left(1 \times 10^{5} /\right.$ well $)$ were cultured in another 6 -well dish. The conditioned medium for SMCs was obtained from ECs or fibroblasts. The medium to conditionally culture SMCs was refreshed with a mixed medium (the one which have cultured ECs and DMEM, 3:1] [25]. SMCs were used for the following experiments at day 3 and day 6.

\section{Von Kossa staining}

Calcium deposition in cultured SMCs was investigated by von Kossa staining as previously described [29]. SMCs were washed twice with phosphate buffered saline (PBS), and fixed with 4\% paraformaldehyde for $15 \mathrm{~min}$ at room temperature. The cells were then washed three times with distilled water, and 3\% silver nitrate solution was added into each well. The cells were exposed to ultraviolet light for $60 \mathrm{~min}$. Then the cells were washed with distilled water and incubated with $5 \%$ sodium thiosulfate for 5 min. Calciumphosphate depositions were observed by light microscope and photographed for black area indicating deposited calcium-phosphate, and the calcification area (black area) was analyzed using the software of Image J 1.48. 


\section{Cellular Physiology Cell Physiol Biochem 2018;49:2371-2381 \begin{tabular}{ll|l} 
and Biochemistry Published online: 28 September 2018 & $\begin{array}{l}\text { (c) } 2018 \text { The Author(s). Published by S. Karger AG, Basel } \\
\text { www.karger.com/cpb }\end{array}$ \\
\hline
\end{tabular} \\ Meng et al.: ECs Promote Calcification in SMCs of SHR}

\section{Quantification of calcium deposition}

SMCs were washed three times with PBS and decalcified with $0.6 \mathrm{mmol} / \mathrm{L} \mathrm{HCl}$ at $4^{\circ} \mathrm{C}$ for $24 \mathrm{~h} \mathrm{[30].}$ The content of calcium in the supernatants of $\mathrm{HCl}$ was determined colorimetrically by the o-cresolphthalein complexone method using the Calcium Colorimetric Assay Kit (BioVision Inc., Milpitas, California, USA). Calcium content was normalized to total cell protein that was dectected by Protein Assay Kit (Beyotime Biological technology Inc., Haimen, China), and expressed as $\mu \mathrm{g} / \mathrm{mg}$ protein.

\section{ALP activity}

SMCs were lysed with $1 \%$ Triton X-100 in PBS at $4^{\circ} \mathrm{C}$ for $1 \mathrm{~h}$, and then centrifuged at $12000 \mathrm{~g}$ for 5 min at $4^{\circ} \mathrm{C}$ [31]. The supernatant was used to analyze ALP activity and protein concentration. ALP activity was measured colorimetrically using ALP Assay Kit (Beyotime, China). One unit of the activity was defined as 1 nmol of p-nitrophenol produced at $37^{\circ} \mathrm{C}$ in $30 \mathrm{~min}$. Results were normalized by total cell protein, and ALP activity was expressed as unit/mg protein.

Western blot analysis

Total protein of ECs and SMCs were extracted in the radio immunoprecipitation assay buffer (Beyotime, China). After centrifuging, supernatants were collected for the determination of protein concentrations. Equal protein $(50 \mu \mathrm{g})$ was loaded onto $10 \%$ SDS - polyacrylamide gels and transferred to PVDF membranes (Beyotime, China). The membranes were blocked with $5 \%$ bovine serum albumin in TBST at room temperature for $1 \mathrm{~h}$, then incubated with primary antibodies: rabbit anti-BMP2 polyclonal antibody (Abcam, Boston, Massachusetts, USA; dilution 1:300), or anti-Runx2 polyclonal antibody (Abcam, USA; dilution 1:500), or rabbit anti-Msx2 polyclonal antibody (Santa Cruz Biotechnology, California, USA, dilution 1:500), or rabbit anti-Osterix polyclonal antibody (Abcam, USA; dilution 1:300), or rabbit anti-MMP-2 polyclonal antibody (Abcam, USA; dilution 1:500), or rabbit anti-MMP-9 polyclonal antibody (Abcam, USA; dilution 1:500), or rabbit anti- $\beta$-actin polyclonal antibody (Santa Cruz, USA, dilution 1:500) overnight at $4^{\circ} \mathrm{C}$. After washed with TBST three times, membranes were incubated with horseradish peroxidase conjugated goatanti-rabbit secondary antibody (Santa Cruz, dilution 1:1000) for $1 \mathrm{~h}$ at $37^{\circ} \mathrm{C}$. Immunodetections were performed with the Enhanced Chemiluminescence Kit (Beyotime, China).

Statistical Analysis

Data are presented as mean \pm SD. The significance of differences was analyzed with Student's t-test or ANOVA followed by Student-Newmann-Keuls multiple comparison tests. Difference was considered statistically significant when the $P$ value was less than 0.05 .

\section{Results}

ECs increased calcium deposition in SMCs from SHR

Von Kossa staining and quantification of calcium content were employed to assess the calcium deposition of SMCs from Wistar rats and SHR (Fig. 1A-C). There was no statistical difference in the extent of calcification between SHR and Wistar rats at the confluence of SMCs (day 0). The calcification area and calcium content of SMCs of SHR significantly increased after 6 days, whereas the calcification area and calcium content of SMCs of Wistar rats at day 6 were not significantly different from that of day 0, indicating SMCs of SHR have the ability to calcify spontaneously. Both the co-cultured and conditionally cultured SMCs of SHR had increased calcification area and calcium content compared with the SMCs without ECs at day 6 (Fig. 1B and C). However, there were no statistical differences in calcification area and calcium content between SMCs without ECs, conditionally cultured SMCs and cocultured SMCs from Wistar rats (Fig. 1B and C). Compared with SMCs without fibroblasts, SMCs co-cultured with fibroblasts and cultured with the medium of fibroblasts were not statistically different in calcification area and calcium content (Fig. 2A-C). These evidences indicated that ECs have the capability to promote the calcification of SMCs from SHR. 
Fig. 1. Von Kossa staining, quantification of calcium content and ALP activity in SMCs co-cultured and conditionally cultured with ECs. A, Von kossa staining of SMCs. B, Colorimetric measurement of calcification area for von kossa staining. C, Calcium content of SMCs. D, ALP activity of SMCs. Dashed line, Wistar rats. Solid line, SHR. CW, culture without ECs (open circles). CM, culture with the medium of ECs (open squares). CC, co-culture with ECs (open triangles). * $\mathrm{P}<0.05$ or ${ }^{* *} \mathrm{P}<0.01$ vs. SMCs of SHR without
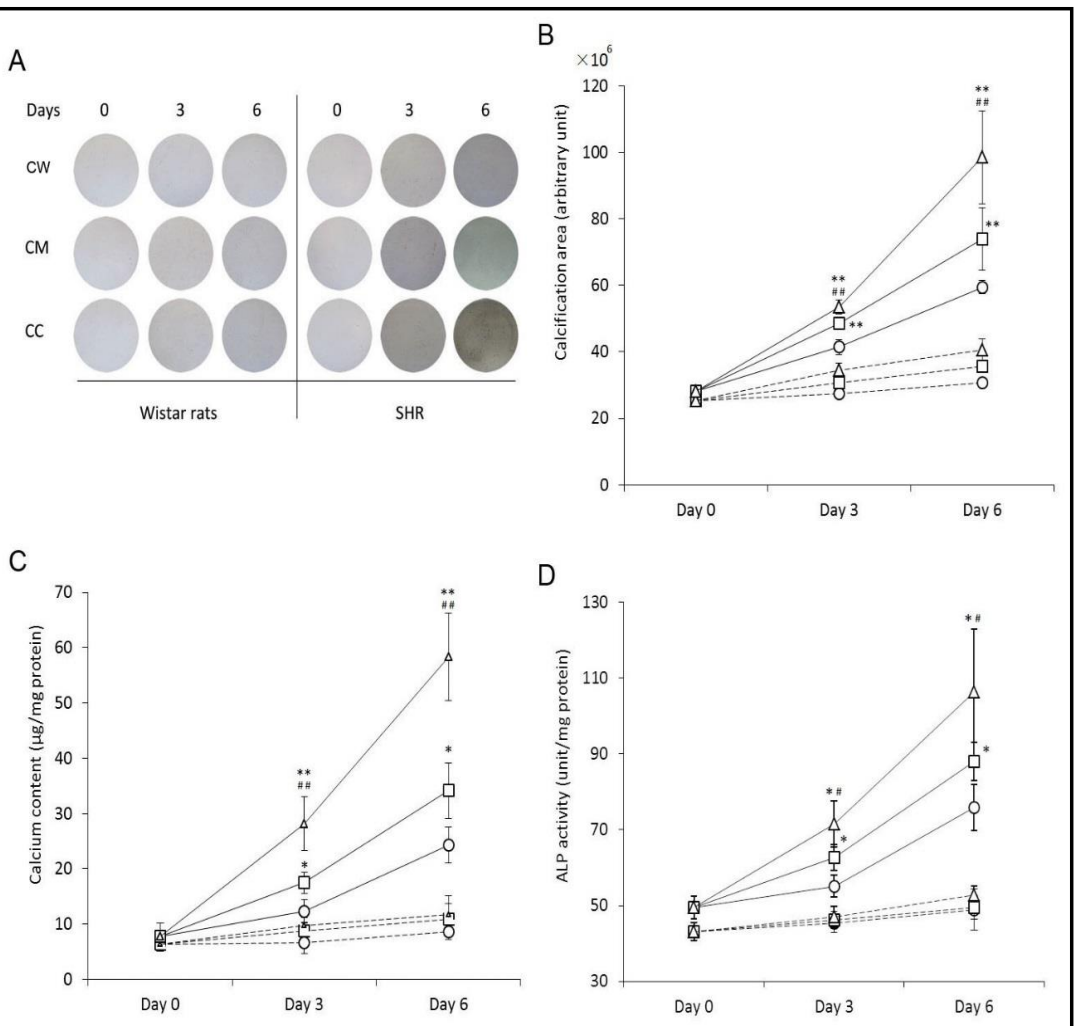

D

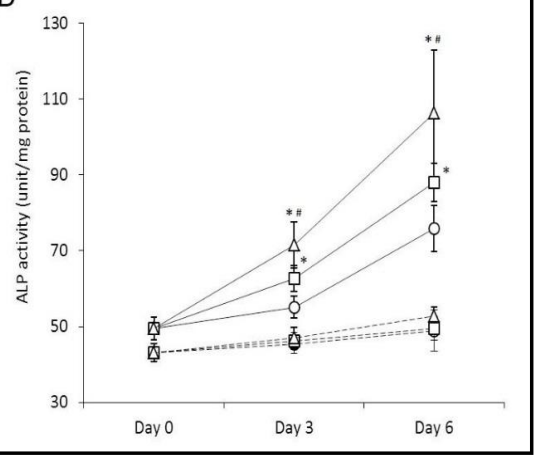

ECs at the same time point. ${ }^{\#} \mathrm{P}<0.05$ or ${ }^{\# \#} \mathrm{P}<0.01$ vs. SMCs of SHR cultured with the medium of ECs at the same time point.

Fig. 2. Von Kossa staining, quantification of calcium content and ALP activity in SMCs co-cultured and conditionally cultured with fibroblasts after 6 days. A, Von kossa staining of SMCs. $\mathrm{B}$, Colorimetric measurement of calcification area for von kossa staining. C, Calcium content of SMCs. D, ALP activity of SMCs. CWF, culture without fibroblasts (white column). CMF, culture with the medium of fibroblasts (grey column). CCF, coculture with fibroblasts (black column). There were no statistically significant differences between CWF, CMF and CCF in the same type of SMCs.

\section{ECs promoted osteogenic transition of SMCs from SHR}

ALP, a bone-related protein, is necessary for mineralization. The activity of ALP is an early marker of osteogenic conversion [9]. As shown in Fig. 1D, compared with the SMCs without ECs, both the conditionally cultured and the co-cultured SMCs of SHR had an enhanced ALP activity at day 6. Nevertheless, there were no statistical differences in ALP activity between the SMCs without ECs, the co-cultured SMCs and conditionally cultured SMCs of Wistar 
Fig. 3. The expressions of BMP2, Runx2, Msx2 and Osterix in SMCs from Wistar rats and SHR at day 6. CW, culture without ECs (white column). CM, culture with the medium of ECs (grey column). CC, co-culture with ECs (black column). ${ }^{*} \mathrm{P}<0.05$ or ${ }^{* *} \mathrm{P}<0.01$ vs. SMCs of SHR without ECs. ${ }^{\#} \mathrm{P}<0.05$ or \#\# $\mathrm{P}<0.01$ vs. SMCs of SHR cultured with the medium of ECs.

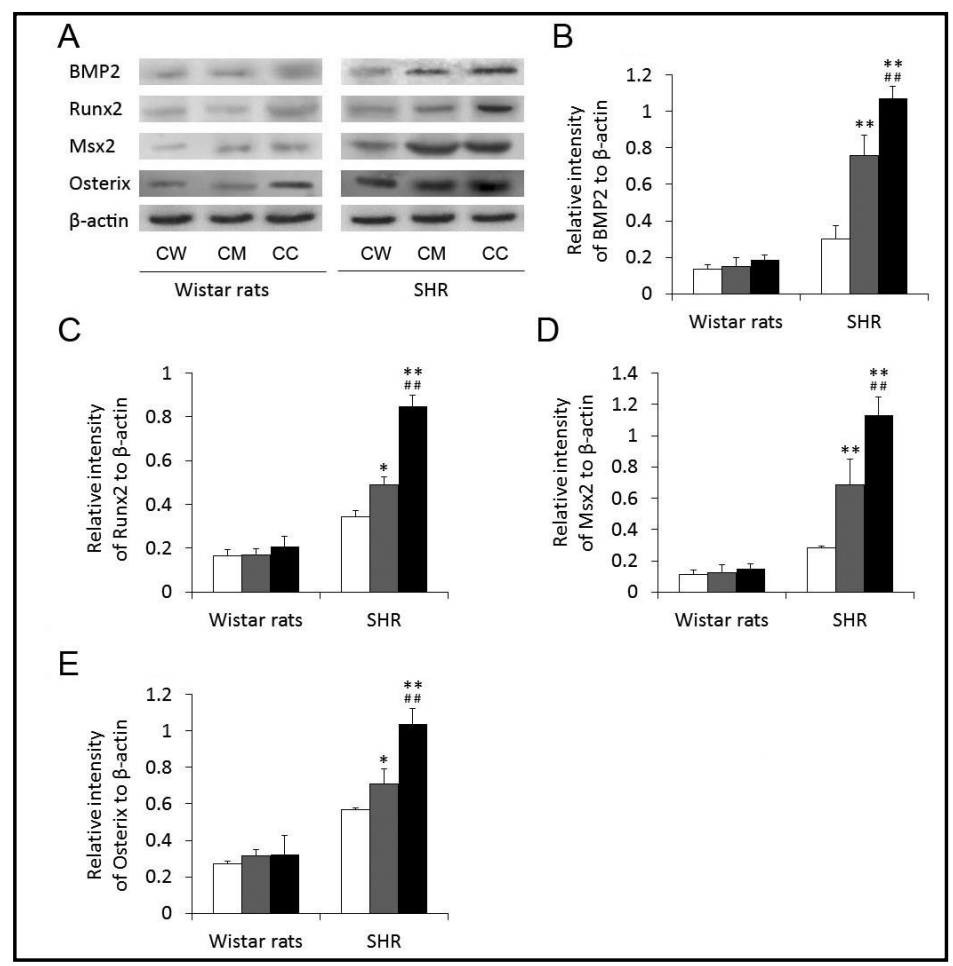

Fig. 4. The expressions of MMP-2 and MMP-9 in SMCs and ECs from Wistar rats and SHR after cultured for 6 days. A-C, The expressions of MMP-2 and MMP-9 in SMCs of Wistar rats and SHR. CW, culture without ECs (white column). CM, culture with the medium of ECs (grey column). CC, co-culture with ECs (black column). D-F, The expressions of MMP-2 and MMP9 in ECs of Wistar rats and SHR. CWS, culture without SMCs (white column). CCS, co-culture with SMCs (black column). ${ }^{* *} \mathrm{P}<0.01$ vs. ECs of SHR cultured without SMCs.

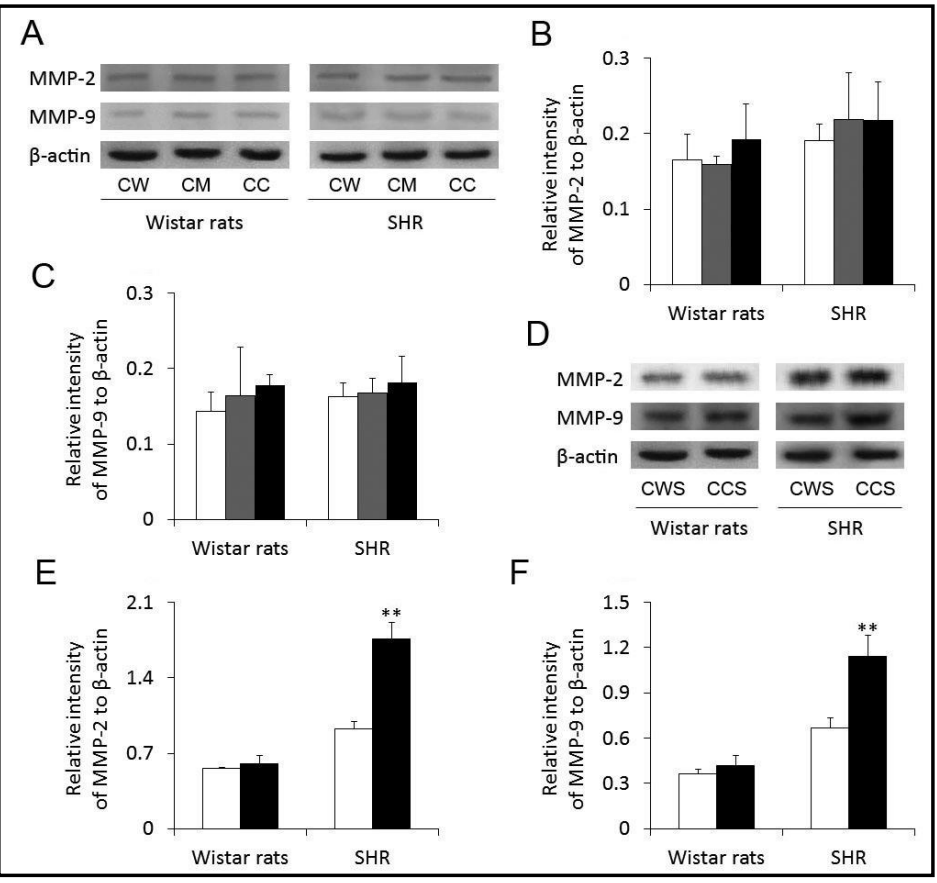

rats. From Fig. 2D, we found that ALP activity had no statistical differences between SMCs without fibroblasts, SMCs co-cultured with fibroblasts and SMCs cultured with the medium of fibroblasts in both Wistar rats and SHR. These results demonstrated that ECs promote the osteogenic transition of SMCs of SHR rather than that of Wistar rats.

ECs promoted the expression of calcification-promoting proteins in SMCS from SHR

BMP2 is a crucial protein promoting vascular calcification. The effect of BMP2 is accomplished by up-regulating the expression of Osterix through two distinct transcription KARGER 
Fig. 5. Calcium content (A) and the expression levels of BMP2, Runx2, Msx2 and Osterix (B-F) in conditionally cultured or co-cultured SMCs of SHR were decreased by SB3CT (black column) treatment for 6 days. Since SB-3CT was dissolved in DMSO, the same concentration of DMSO (5\%) was used as a negative vehicle control in the experiment (grey column). And there were no significant differences in both calcification content and the expression levels of pro-calcification protein between DMSO groups (grey column) and the groups without DMSO (white column). CW, culture without ECs. CM, culture with the medium of ECs. CC, co-culture with ECs. ${ }^{*} \mathrm{P}<0.05,{ }^{* *} \mathrm{P}<0.01$.
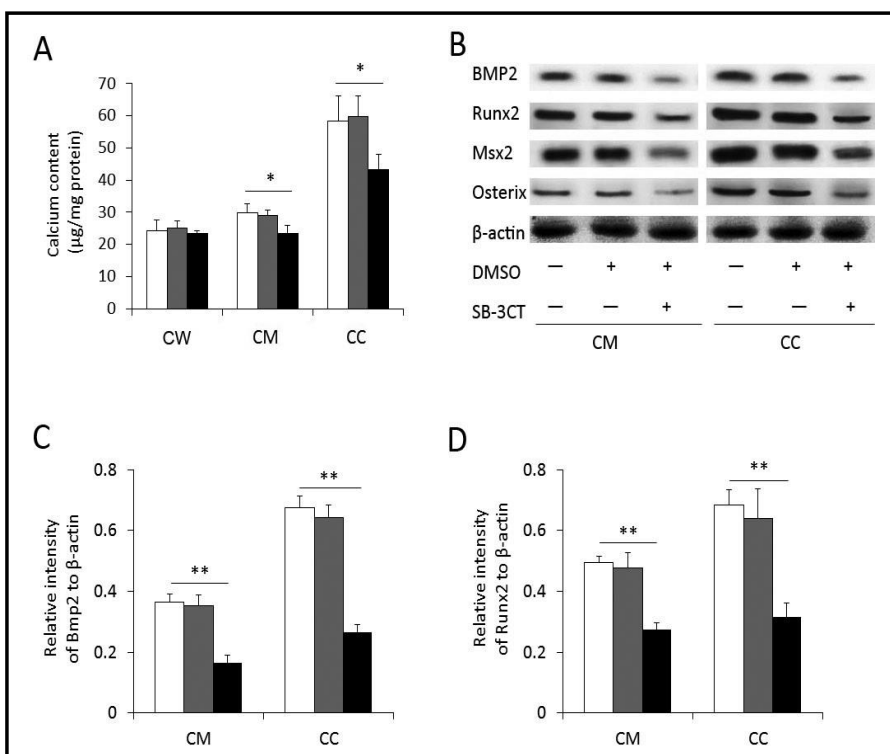

D
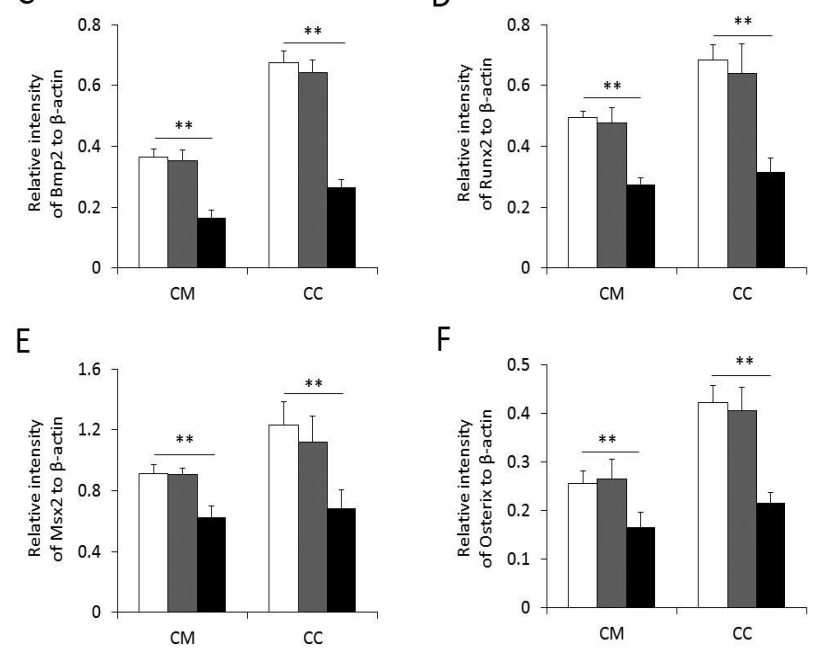

F

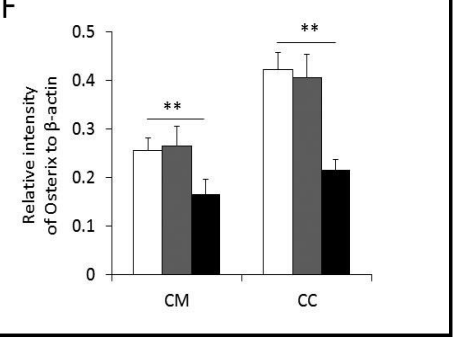

factors, Runx2 and Msx2 [14, 15]. After 6 days, the expression levels of BMP2, Msx2, Runx2 and Osterix in both the conditionally cultured SMCs and the co-cultured SMCs of SHR were significantly higher than that without ECs. Nevertheless, there were no statistical differences in the expression of each of the proteins between the SMCs without ECs, the co-cultured SMCs and conditionally cultured SMCs from Wistar rats (Fig. 3). The present study indicated that ECs of SHR up-regulate the expressions of calcification-promoting proteins, thereby promoting calcification in SMCs from SHR.

\section{MMP-2 and MMP-9 secreted from ECs facilitate calcification of SMCs in SHR}

MMP-2 and MMP-9 have been found to be involved in the pathogenesis of vascular calcification $[23,24]$. In the present study, compared with the SMCs without ECs, we found no significant differences in expression levels of MMP-2 and MMP-9 in both the coculture pattern and the conditioned culture pattern of SMC of SHR or Wistar rats (Fig. 4AC). However, the expression levels of MMP-2 and MMP-9 in co-cultured ECs of SHR were remarkably higher than that without SMCs of SHR, and there were no significant differences between ECs from Wistar rats (Fig. 4D-F).

Our previous study showed that both the expression levels and activity of MMP-2 and MMP-9 in ECs of SHR were higher than that of Wistar rats [32]. To demonstrate MMP-2 and MMP-9 secreted from ECs of SHR facilitate the calcification of SMCs from SHR, SB-3CT (200 $\mu \mathrm{mol} / \mathrm{L}$ in DMSO, Santa Cruz Biotechnology, California, USA, to a concentration of 10 $\mu \mathrm{mol} / \mathrm{L}$ ), a specific inhibitor of gelatinases, was added into the DMEM [33]. As shown by Fig. 5, after treatment with SB-3CT for 6 days, calcium content and the expression levels of BMP2, Runx2, Msx2 and Osterix were significantly decreased in both the conditionally cultured and co-cultured SMCs of SHR. These results suggested that elevated expressions of MMP-2 and MMP-9 in ECs from SHR might facilitate calcification of SMCs. 


\section{Cellular Physiology Cell Physiol Biochem 2018;49:2371-2381 \begin{tabular}{ll|l} 
and Biochemistry Published onlIne: 28 September 2018 & $\begin{array}{l}\text { (c) } 2018 \text { The Author(s). Published by S. Karger AG, Basel } \\
\text { www.karger.com/cpb }\end{array}$ \\
\hline
\end{tabular} \\ Meng et al.: ECs Promote Calcification in SMCs of SHR}

\section{Discussion}

Hypertension is intimately linked with vascular calcification, and endothelial dysfunction is closely correlated with the progression of hypertension. However, the role of ECs in vascular calcification of hypertension remains unclear. The present study showed that the calcium deposition and ALP activity of both conditionally cultured and co-cultured SMCs from SHR were higher than that without ECs, but there were no statistical differences in calcium deposition and ALP activity between the three groups in the SMCs from Wistar rats. To exclude the possibility that other cells than ECs have effects on spontaneous calcification of SMCs in the culture system, a negative control cell is prerequisite. In this study fibroblasts were served as the negative control. As Fig. 2 shows, fibroblasts were incapable of promoting calcification and osteogenic transition of SMCs from either Wistar rats or SHR. These results indicated ECs have the capability to promote the calcification in SMCs of SHR. In addition, the present study found SMCs of SHR spontaneously calcified in DMEM containing 10\% FBS without any other calcification stimulus, which was consistent with the report of Kanemaru et al. [34].

Vascular calcification is regulated by a number of factors. BMP2, a crucial promoter of vascular calcification, is a member of transforming growth factor- $\beta$ superfamily. Its downstream effects are accomplished by the upregulation of key osteogenic transcription factors, including Runx2 and Msx2 which are mediators of vascular calcification [15, 35]. The expression of Runx2 in SMCs serves as an early, definitive marker of osteoblastic differentiation, the initial step in vascular calcification [9]. Osterix, a Sp1 transcription family member, is a key regulator of osteoblast progenitors. BMP2 regulates Osterix expression independently through Runx2 and Msx2 [14, 15]. Kanemaru et al. demonstrated that aortic SMCs from SHR spontaneously calcified via Msx2-Osterix signaling pathway [34]. The present study showed that the expression levels of BMP2, Msx2, Runx2 and Osterix in SMCs of SHR were significantly higher than that without ECs after 6 days of co-culture and conditioned culture. Accordingly, the extent of calcification and ALP activity in both co-cultured and conditionally cultured SMCs of SHR were higher than that without ECs. These evidences indicated that the calcification-promoting effect of ECs is achieved by up-regulating the expression of proteins in BMP2-Runx2-Osterix and BMP2-Msx2-Osterix signaling pathway in SMCs of SHR.

In this study, the calcium deposition and the expression levels of calcification-promoting proteins in SMCs of SHR were increased after treatment with the medium of ECs, which indicated that soluble factors secreted by ECs might be involved in the calcificationpromoting effect of ECs from SHR. MMPs are the members of a large family of proteins which are characterized by an active site containing a metal atom. The gelatinases (MMP-2 and MMP-9) are the most extensively investigated MMPs in the vasculature. MMP-2 and MMP-9 can be secreted by ECs and SMCs, and have the functions to cleave the basement membrane, type IV collagen, laminin and elastin [36,37]. In hypertensive patients, plasma levels and activities of MMP-2 and MMP-9 were found to be enhanced, which was directly linked to increased arterial distensibility in vitro and in vivo, and recognized as the principal inducer of vascular remodeling [36, 38]. Sasaki et al. reported that MMP-2 deficiency impaired aortic atherosclerotic calcification in ApoE-deficient mice and inhibited mineral deposition induced by $\beta$-glycerophosphate [22]. Chen et al. revealed that activation of MMP-2 and MMP9 lead to vascular calcification in chronic kidney diseases rats [23]. In our previous study, both the expression levels and activity of MMP-2 and MMP-9 in ECs of SHR were higher than that of Wistar rats [32], and gelatinases could promote calcification of SMCs by up-regulating BMP-2 $[39,40]$. This study showed that calcium deposition and the expressive levels of BMP2, Runx2, Msx2 and Osterix in conditionally cultured SMCs of SHR were higher than that without ECs after cultured with the medium of ECs from SHR for 6 days, but there were no 


\section{Cellular Physiology Cell Physiol Biochem 2018;49:2371-2381 \begin{tabular}{ll|l} 
and Biochemistry & DOI: 10.1159/000493837 & $\begin{array}{l}\text { O } 2018 \text { The Author(s). Published by S. Karger AG, Basel } \\
\text { www.karger.com/cpb }\end{array}$ \\
\cline { 2 - 3 }
\end{tabular} \\ Meng et al.: ECs Promote Calcification in SMCs of SHR}

statistical differences in the expression levels of MMP-2 and MMP-9 between conditionally cultured SMCs of SHR and the SMCs without ECs. Furthermore, SB-3CT, a specific gelatinases inhibitor, had decreased the calcium content and expression levels of these proteins in conditionally cultured SMCs from SHR. Those results suggested that elevated expressions of MMP-2 and MMP-9 in ECs from SHR might promote the calcification in SMCs of SHR.

In the present study, we found that both calcium deposition and the expression levels of these pro-calcification proteins in the co-cultured SMCs of SHR were higher than that in the conditionally cultured SMCs, and the expressive levels of MMP-2 and MMP-9 in the cocultured ECs of SHR were increased compared with that cultured without SMCs, nevertheless, there were no significant differences in MMP-2 and MMP-9 levels between the three groups of SMCs from SHR, which indicated that the cross-talk between ECs and SMCs of SHR could intensify the calcification in the SMCs of SHR and increase the expression levels of MMP2 and MMP-9 in ECs of SHR. Moreover, after treatment with SB-3CT, the calcium content and expression levels of BMP-2, Runx2, Msx2 and Osterix in the co-cultured SMCs of SHR decreased. Those results suggested that the cross-talk between ECs and SMCs of SHR is able to elevate the expressions of MMP-2 and MMP-9 in ECs from SHR, thereby enhance the calcification in co-cultured SMCs of SHR.

\section{Conclusion}

In summary, these results indicate that ECs of SHR have the ability to drive the calcification of aortic SMCs isolated from SHR. Elevated expressions of MMP-2 and MMP-9 from ECs might facilitate the calcification of SMCs. These findings provide novel insight into the pathogenesis of vascular calcification in hypertension.

\section{Acknowledgements}

This research was supported by grants from Youth Fund of Peking Union Medical College (No. 3332013020).

\section{Disclosure Statement}

All authors declare that they have no potential conflict of interests.

\section{References}

1 Speer MY, Yang HY, Brabb T, Leaf E, Look A, Lin WL, Frutkin A, Dichek D, Giachelli CM: Smooth muscle cells give rise to osteochondrogenic precursors and chondrocytes in calcifying arteries. Circ Res 2009;104:733741.

-2 Kalra SS, Shanahan CM: Vascular calcification and hypertension: cause and effect. Ann Med 2012;44:S8592.

-3 Blacher J, Guerin AP, Pannier B, Marchais SJ, London GM: Arterial calcifications, arterial stiffness, and cardiovascular risk in end-stage renal disease. Hypertension 2001;38:938-942.

-4 Toussaint ND, Lau KK, Strauss BJ, Polkinghorne KR, Kerr PG: Associations between vascular calcification, arterial stiffness and bone mineral density in chronic kidney disease. Nephrol Dial Transplant 2008;23:586-593.

5 Temmar M, Liabeuf S, Renard C, Czernichow S, Esper NE, Shahapuni I, Presne C, Makdassi R, Andrejak M, Tribouilloy C, Galan P, Safar ME, Choukroun G, Massy Z: Pulse wave velocity and vascular calcification at different stages of chronic kidney disease. J Hypertens 2010;28:163-169. 


\section{Cellular Physiology Cell Physiol Biochem 2018;49:2371-2381 \begin{tabular}{ll|l} 
and Biochemistry Published online: 28 September 2018 & $\begin{array}{l}\text { (c) } 2018 \text { The Author(s). Published by S. Karger AG, Basel } \\
\text { www.karger.com/cpb }\end{array}$ \\
\hline
\end{tabular} \\ Meng et al.: ECs Promote Calcification in SMCs of SHR}

6 McEniery CM, McDonnell BJ, So A, Aitken S, Bolton CE, Munnery M, Hickson SS, Yasmin, Maki-Petaja KM, Cockcroft JR, Dixon AK, Wilkinson IB: Aortic calcification is associated with aortic stiffness and isolated systolic hypertension in healthy individuals. Hypertension 2009;53:524-531.

7 Golestani R, Tio R, Zeebregts CJ, Zeilstra A, Dierckx RA, Boersma HH, Hillege HL, Slart RH: Abdominal aortic calcification detected by dual X-ray absorptiometry: A strong predictor for cardiovascular events. Ann Med 2010;42:539-545.

8 Verbeke F, Van Biesen W, Honkanen E, Wikstrom B, Jensen PB, Krzesinski JM, Rasmussen M, Vanholder R, Rensma PL: Prognostic value of aortic stiffness and calcification for cardiovascular events and mortality in dialysis patients: outcome of the calcification outcome in renal disease (CORD) study. Clin J Am Soc Nephrol 2011;6:153-159.

-9 Johnson RC, Leopold JA, Loscalzo J: Vascular calcification: pathobiological mechanisms and clinical implications. Circ Res 2006;99:1044-1059.

10 Wu M, Rementer C, Giachelli CM: Vascular calcification: an update on mechanisms and challenges in treatment. Calcif Tissue Int 2013;93:365-373.

11 Steitz SA, Speer MY, Curinga G, Yang HY, Haynes P, Aebersold R, Schinke T, Karsenty G, Giachelli CM: Smooth muscle cell phenotypic transition associated with calcification: upregulation of $\mathrm{Cbfa} 1$ and downregulation of smooth muscle lineage markers. Circ Res 2001;89:1147-1154.

12 Hruska KA, Mathew S, Saab G: Bone morphogenetic proteins in vascular calcification. Circ Res 2005;97:105-114.

13 Ducy P, Zhang R, Geoffroy V, Ridall AL, Karsenty G: Osf2/Cbfa1: a transcriptional activator of osteoblast differentiation. Cell 1997;89:747-754.

14 Nakashima K, Zhou X, Kunkel G, Zhang Z, Deng JM, Behringer RR, de Crombrugghe B: The novel zinc fingercontaining transcription factor osterix is required for osteoblast differentiation and bone formation. Cell 2002;108:17-29.

15 Matsubara T, Kida K, Yamaguchi A, Hata K, Ichida F, Meguro H, Aburatani H, Nishimura R, Yoneda T: BMP2 regulates Osterix through Msx2 and Runx2 during osteoblast differentiation. J Biol Chem 2008;283:2911929125.

16 Yao Y, Jumabay M, Ly A, Radparvar M, Cubberly MR, Bostrom KI: A role for the endothelium in vascular calcification. Circ Res 2013;113:495-504.

17 Kaplan FS, Xu M, Seemann P, Connor JM, Glaser DL, Carroll L, Delai P, Fastnacht-Urban E, Forman SJ, Gillessen-Kaesbach G, Hoover-Fong J, Koster B, Pauli RM, Reardon W, Zaidi SA, Zasloff M, Morhart R, Mundlos S, Groppe J, Shore EM: Classic and atypical fibrodysplasia ossificans progressiva (FOP) phenotypes are caused by mutations in the bone morphogenetic protein (BMP) type I receptor ACVR1. Hum Mutat 2009;30:379-390.

18 Cola C, Almeida M, Li D, Romeo F, Mehta JL: Regulatory role of endothelium in the expression of genes affecting arterial calcification. Biochem Biophys Res Commun 2004;320:424-427.

19 Inoue T, Node K: Vascular failure: A new clinical entity for vascular disease. J Hypertens 2006;24:21212130.

20 DeLano FA, Schmid-Schonbein GW: Proteinase activity and receptor cleavage: mechanism for insulin resistance in the spontaneously hypertensive rat. Hypertension 2008;52:415-423.

-21 Wu KI, Schmid-Schonbein GW: Nuclear factor kappa B and matrix metalloproteinase induced receptor cleavage in the spontaneously hypertensive rat. Hypertension 2011;57:261-268.

22 Sasaki T, Nakamura K, Sasada K, Okada S, Cheng XW, Suzuki T, Murohara T, Sato K, Kuzuya M: Matrix metalloproteinase-2 deficiency impairs aortic atherosclerotic calcification in ApoE-deficient mice. Atherosclerosis 2013;227:43-50.

23 Chen NX, O'Neill KD, Chen X, Kiattisunthorn K, Gattone VH, Moe SM: Activation of arterial matrix metalloproteinases leads to vascular calcification in chronic kidney disease. Am J Nephrol 2011;34:211219.

24 Wang L, Han Y, Shen Y, Yan ZQ, Zhang P, Yao QP, Shen BR, Gao LZ, Qi YX, Jiang ZL: Endothelial insulin-like growth factor-1 modulates proliferation and phenotype of smooth muscle cells induced by low shear stress. Ann Biomed Eng 2014;42:776-786.

25 Shin V, Zebboudj AF, Bostrom K: Endothelial cells modulate osteogenesis in calcifying vascular cells. J Vasc Res 2004;41:193-201. 


\section{Cellular Physiology Cell Physiol Biochem 2018;49:2371-2381

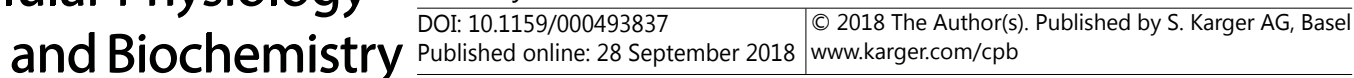 \\ Meng et al.: ECs Promote Calcification in SMCs of SHR}

26 Lee H, Shi W, Tontonoz P, Wang S, Subbanagounder G, Hedrick CC, Hama S, Borromeo C, Evans RM, Berliner JA, Nagy L: Role for peroxisome proliferator-activated receptor alpha in oxidized phospholipid-induced synthesis of monocyte chemotactic protein-1 and interleukin-8 by endothelial cells. Circ Res 2000;87:516521.

27 Suh JH, Yoon JS, Kim HW, Jo KH: Adventitial fibroblast abormality in thoracic aortic aneurysms and aortic dissections. Korean J Thorac Cardiovasc Surg 2011;44:406-412.

28 An SJ, Liu P, Shao TM, Wang ZJ, Lu HG, Jiao Z, Li X, Fu JQ: Characterization and functions of vascular adventitial fibroblast subpopulations. Cell Physiol Biochem 2015;35:1137-1150.

29 Balderman JA, Lee HY, Mahoney CE, Handy DE, White K, Annis S, Lebeche D, Hajjar RJ, Loscalzo J, Leopold JA: Bone morphogenetic protein-2 decreases microRNA-30b and microRNA-30c to promote vascular smooth muscle cell calcification. J Am Heart Assoc 2012;1:e003905.

-30 Jono S, Peinado C, Giachelli CM: Phosphorylation of osteopontin is required for inhibition of vascular smooth muscle cell calcification. J Biol Chem 2000;275:20197-20203.

-31 Zhu D, Mackenzie NC, Millan JL, Farquharson C, MacRae VE: A protective role for FGF-23 in local defence against disrupted arterial wall integrity? Mol Cell Endocrinol 2013;372:1-11.

32 Wang B, Li BW, Li HW, Li AL, Yuan XC, Wang Q Xiu RJ: Enhanced matrix metalloproteinases-2 activates aortic endothelial hypermeability, apoptosis and vascular rarefaction in spontaneously hypertensive rat. Clin Hemorheol Microcirc 2014;57:325-338.

-33 De Munck J, Van den Steen PE, Mine A, Van Landuyt KL, Poitevin A, Opdenakker G, Van Meerbeek B: Inhibition of enzymatic degradation of adhesive-dentin interfaces. J Dent Res 2009;88:1101-1106.

-34 Kanemaru K, Seya K, Miki I, Motomura S, Furukawa K: Calcification of aortic smooth muscle cells isolated from spontaneously hypertensive rats. J Pharmacol Sci 2008;106:280-286.

35 Rong S, Zhao X, Jin X, Zhang Z, Chen L, Zhu Y, Yuan W: Vascular calcification in chronic kidney disease is induced by bone morphogenetic protein-2 via a mechanism involving the Wnt/beta-catenin pathway. Cell Physiol Biochem 2014;34:2049-2060.

-36 Lemarie CA, Tharaux PL, Lehoux S: Extracellular matrix alterations in hypertensive vascular remodeling. J Mol Cell Cardiol 2010;48:433-439.

37 Galis ZS, Khatri JJ: Matrix metalloproteinases in vascular remodeling and atherogenesis: the good, the bad, and the ugly. Circ Res 2002;90:251-262.

-38 Androulakis E, Tousoulis D, Papageorgiou N, Latsios G, Siasos G, Stefanadis C: The role of matrix metalloproteinases in essential hypertension. Curr Top Med Chem 2012;12:1149-1158.

-39 Zhao YG, Meng FX, Li BW, Sheng YM, Liu MM, Wang B, Li HW, Xiu RJ: Gelatinases promote calcification of vascular smooth muscle cells by up-regulating bone morphogenetic protein-2. Biochem Biophys Res Commun 2016;470:287-293.

-40 Luong TTD, Schelski N, Boehme B, Makridakis M, Vlahou A, Lang F, Pieske B, Alesutan I, Voelkl J: Fibulin-3 Attenuates Phosphate-Induced Vascular Smooth Muscle Cell Calcification by Inhibition of Oxidative Stress. Cell Physiol Biochem 2018;46:1305-1316. 